\title{
Post-Coital Seepage - A Rarely-Discussed, Yet Common Inconvenience for Most Women: A Main Systematic Review
}

\author{
Nicole Pepe ${ }^{1 *}$ and Michael Ingber ${ }^{1,2}$ \\ ${ }^{1}$ Department of Female Pelvic Medicine \& Reconstructive Surgery, Atlantic Health System, USA \\ ${ }^{2}$ Department of Surgery, Atlantic Health System, USA
}

*Corresponding author: Nicole Pepe, Department of Female Pelvic Medicine \& Reconstruction Surgery, Atlantic Health System, 100 Madison Ave, Morristown, NJ, USA.

Received Date: July 07, 2021

Published Date: October 07, 2021

\begin{abstract}
Women have a significant number of sexual dysfunctions that are not often discussed in a clinical setting. This study identified post-coital seepage of semen as a prevalent issue among sexually-active women. A survey was constructed to include questions on female sexual hygiene to quantify the discomfort women may experience after intercourse. Approximately half (52\%) of women involved in the study experienced semen seepage or dripping of fluids after intercourse, with $41 \%$ of women admitting to being moderately or severely bothered. Multiple women also admitted further to various complaints including sensation of feeling unclean, vaginal odor, and/or vaginal yeast infections after vaginal intercourse. We conclude that the prevalence of post-coital semen seepage in sexually-active women is high. Our study found that these women had significant bother not only from the immediate seepage, but also from the prolonged after-effects of odor and discomfort even hours after sex.
\end{abstract}

Keywords: Post-coital; Semen; Discomfort; Intercourse; Sexually active women

\section{Introduction}

Despite the significant number of sexual dysfunctions in women, physicians often avoid discussing these concerns in the office setting [1]. With recent research on the role of the pelvic floor, and recently approved medical therapies for hypoactive sexual desire disorder, physicians have begun to adapt to questioning patients about libido and pain-related sexual dysfunctions. However, pain-related sexual questionnaires often focus on insertional and penetrational dyspareunia, without asking about discomfort minutes, hours, or even the day following sexual intercourse [1]. One common compliant in our ambulatory sexual medicine clinic is the bothersome dripping, odor, and discomfort women experience after sexual activity when no condom is used, and when intravaginal ejaculation occurs. Novel products have been introduced in the past year to address this concern some women have (DripStick, Costa
Mesa CA). However, there is no data on the actual prevalence of this complaint in women.

Previous studies have shown the effects of semen on alterations in the vaginal flora [1]. These changes contribute to a multitude of clinical complaints and diagnoses, including malodor, continuous discharge after intercourse, and bacterial vaginosis (BV). The exposure of semen changes the vaginal flora by increasing the $\mathrm{pH}$ levels, in turn altering the bacterial growth pattern [2]. This implies the persistent presence of semen in the vagina may be one of the causes of malodor and development of BV. Chvapil utilized gas chromatography and demonstrated that the longer period of time semen was present in the vagina, the more likely it resulted in a strong and unattractive vaginal odor [3]. Gallo showed that an incidental diagnosis of BV was correlated with detection of sperm 
on gram stain, and frequent coitus with or without condom use [2].

Our goal in this study was to identify the prevalence of the complaint of continuous seepage of semen and vaginal odor after intercourse and determine the bother in these women.

\section{Materials and Methods}

The research instrument was co-designed by the authors in partnership with a professional research and online survey research company, Centiment (Denver, CO). Respondents were sampled from a diverse geographic representation across the United States. The respondent pool was a statistically representative sample of the target population. Inclusion criteria were age 18 or older, female, heterosexual, sexually-active with regular penile-vaginalintercourse within the previous year. Women were excluded if their primary birth control was male condoms. The survey was administered using a customized interface built on Typeform survey platform and on average took $3 \mathrm{~min}$ from start to completion. Respondents were compensated with a small honorarium for completion.

To ensure respondents were attending to the questions an attention check question was inserted into the survey. Those who answered incorrectly were disqualified from the research sample. The full list of survey questions and answer choices is shown in Tables 1-4 and Charts 1-2.

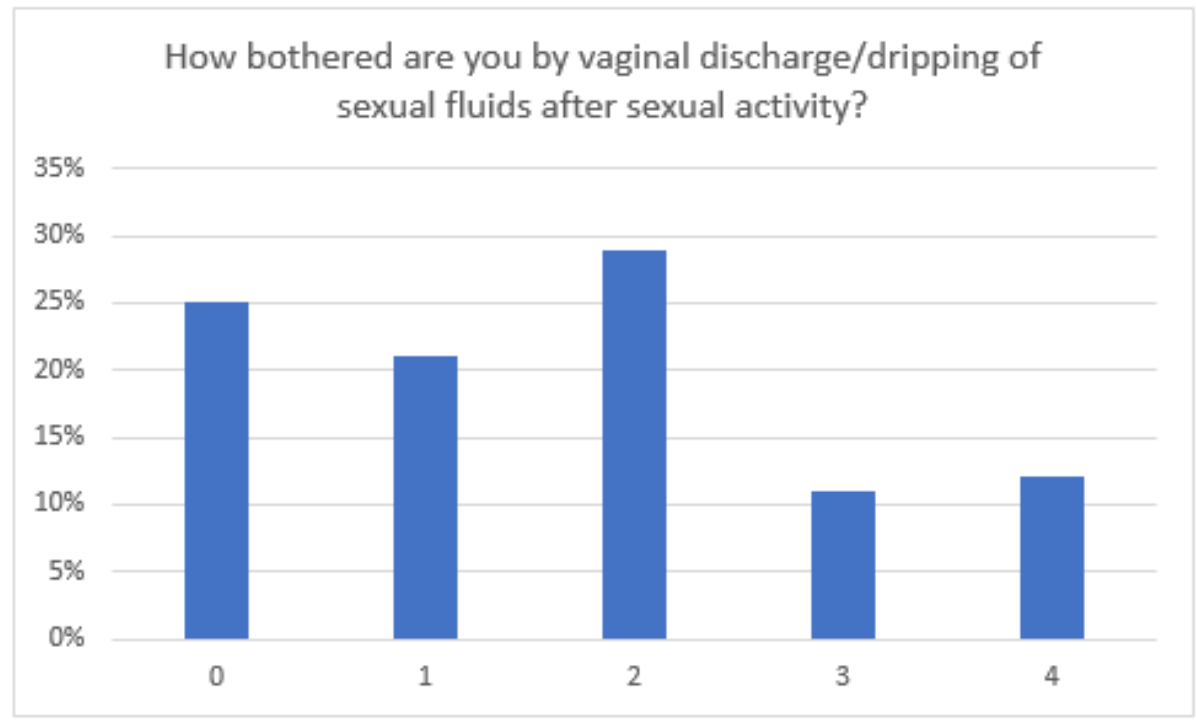

Chart 1: Assessment of how bothered women are by vaginal discharge/dripping of sexual fluids. $0=$ not at all, $2=$ moderately, $4=$ extremely.

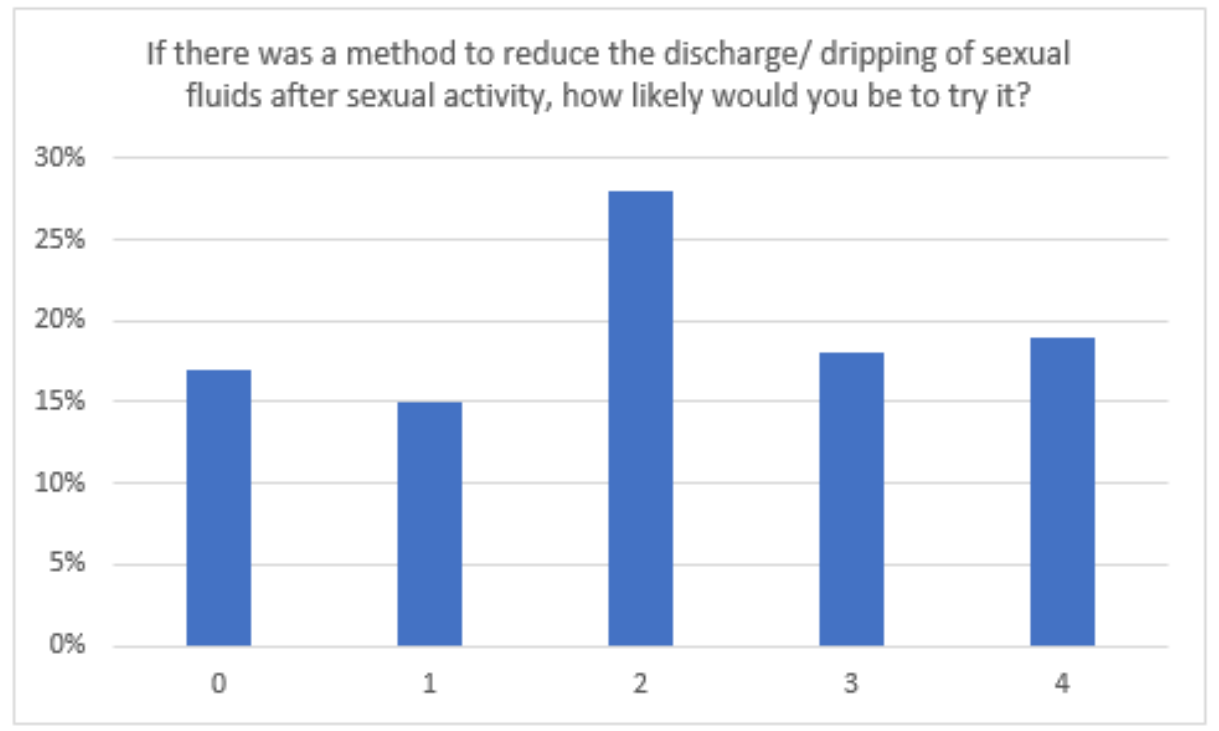

Chart 2: Assessment of women who would be interested in using a method to reduce amount of discharge/ dripping of sexual fluids. $0=$ not at all, 2 = moderately, 4 = extremely. 
Table 1: List of questions regarding population identification.

\begin{tabular}{|c|c|c|}
\hline Question & Answer Choices & Response \\
\hline \multirow{5}{*}{ What is your age? } & 1. $26-40$ yrs. & 1. $30 \%$ \\
\hline & 2. $18-25$ yrs. & 2. $25 \%$ \\
\hline & 3. $41-55$ yrs. & 3. $20 \%$ \\
\hline & 4. $>56$ yrs. & 4. $20 \%$ \\
\hline & 5. $<18$ yrs. & 5. $3 \%$ \\
\hline \multirow[t]{3}{*}{ Please estimate your household income } & 1. $<\$ 49,999$ & 1. $49 \%$ \\
\hline & 2. $\$ 50,000-150,000$ & 2. $43 \%$ \\
\hline & 3. $>\$ 151,000$ & 3. $7 \%$ \\
\hline \multirow{5}{*}{$\begin{array}{l}\text { What is the highest degree or level of school you have } \\
\text { completed? (if currently enrolled, highest degree } \\
\text { received) }\end{array}$} & 1. Some College & 1. $35 \%$ \\
\hline & 2. High School or Equivalent (e.g. GED) & 2. $25 \%$ \\
\hline & 3. Bachelor's Degree & 3. $22 \%$ \\
\hline & $\begin{array}{l}\text { 4. Graduate Degree or Higher (i.e. master's or } \\
\text { Doctoral) }\end{array}$ & 4. $13 \%$ \\
\hline & 5. Other & 5. $2 \%$ \\
\hline \multirow{5}{*}{ Please specify your ethnicity } & 1. White & 1. $66 \%$ \\
\hline & 2. Black or African American & 2. $18 \%$ \\
\hline & 3. Hispanic or Latino & 3. $8 \%$ \\
\hline & 4. Asian/Pacific Islander & 4. $\quad 4 \%$ \\
\hline & 5. Other & 5. $3 \%$ \\
\hline \multirow[t]{4}{*}{ Please share your current relationship status } & 1. Married or Have a Partner & 1. $51 \%$ \\
\hline & 2. Single (Never Married) & 2. $31 \%$ \\
\hline & 3. Divorced/Separated & 3. $12 \%$ \\
\hline & 4. Widowed & 4. $\quad 4 \%$ \\
\hline
\end{tabular}

Table 2: Description of sexual behaviors.

\begin{tabular}{|c|c|c|}
\hline Question & Answer Choices & Response \\
\hline \multirow{4}{*}{ What is your sexual orientation? } & 1. Heterosexual & 1. $82 \%$ \\
\hline & 2. Bisexual & 2. $10 \%$ \\
\hline & 3. Prefer not to answer & 3. $4 \%$ \\
\hline & 4. Homosexual & 4. $2 \%$ \\
\hline \multirow[t]{2}{*}{ Are you sexually active? } & 1. Yes & 1. $69 \%$ \\
\hline & 2. No & 2. $30 \%$ \\
\hline \multirow{5}{*}{$\begin{array}{l}\text { On average, how frequently do you have sexual } \\
\text { intercourse? }\end{array}$} & 1. Weekly & 1. $33 \%$ \\
\hline & 2. Multiple Times per Week & 2. $31 \%$ \\
\hline & 3. Monthly & 3. $19 \%$ \\
\hline & 4. A Few Times per Year & 4. $8 \%$ \\
\hline & 5. Daily & 5. $\quad 7 \%$ \\
\hline \multirow{5}{*}{$\begin{array}{l}\text { What form of birth control/ contraception do you } \\
\text { most frequently use? }\end{array}$} & 1. No active use on contraception & 1. $48 \%$ \\
\hline & 2. Male condoms & 2. $20 \%$ \\
\hline & 3. Oral contraception (i.e. birth control pills) & 3. $17 \%$ \\
\hline & 4. Intrauterine device & 4. $6 \%$ \\
\hline & 5. Other & 5. $7 \%$ \\
\hline \multirow[t]{3}{*}{$\begin{array}{l}\text { How would you describe your current menstrual } \\
\text { status? }\end{array}$} & $\begin{array}{l}\text { 1. Pre-menopause (before menopause: having regular } \\
\text { periods) }\end{array}$ & 1. $58 \%$ \\
\hline & 2. Post-menopausal (after menopause) & 2. $25 \%$ \\
\hline & $\begin{array}{l}\text { 3. Peri-menopause (changes in periods but have not } \\
\text { gone } 12 \text { months without a period) }\end{array}$ & 3. $16 \%$ \\
\hline
\end{tabular}




\begin{tabular}{|l|c|cc|}
\hline \multirow{2}{*}{$\begin{array}{c}\text { Which product have you primarily used during men- } \\
\text { struation (past or present)? }\end{array}$} & $1 . \quad$ Tampon & 1. & $48 \%$ \\
\cline { 2 - 4 } & $2 . \quad$ Sanitary Pad & 2. & $39 \%$ \\
\cline { 2 - 4 } & $3 . \quad$ Do Not Use & 3. & $8 \%$ \\
\cline { 2 - 4 } & $4 . \quad$ Other (e.g. menstrual cup) & 4. & $2 \%$ \\
\hline
\end{tabular}

Table 3: Assessment of women experiencing dripping of sexual fluids.

\begin{tabular}{|c|c|c|}
\hline Question & Answer Choices & Response \\
\hline \multirow{6}{*}{$\begin{array}{l}\text { After sexual activity, which of the following have you } \\
\text { experienced? (Check all that apply) }\end{array}$} & $\begin{array}{l}\text { 1. Discharge/Dripping of Sexual Fluids (e.g. semen, } \\
\text { lubricant) }\end{array}$ & 1. $52 \%$ \\
\hline & 2. None of the above & 2. $31 \%$ \\
\hline & 3. Sensation of Feeling Unclean & 3. $27 \%$ \\
\hline & 4. Urinary Tract Infection (UTI)/ Bladder Infection & 4. $21 \%$ \\
\hline & 5. Vaginal Odor & 5. $20 \%$ \\
\hline & 6. Vaginal/ Yeast Infection & 6. $13 \%$ \\
\hline \multirow[t]{4}{*}{$\begin{array}{l}\text { When do you notice the dripping/ discharge after sexual } \\
\text { activity? (Check all that apply) }\end{array}$} & $\begin{array}{l}\text { 1. Immediately Following Ejaculation (i.e. male or- } \\
\text { gasm) }\end{array}$ & 1. $72 \%$ \\
\hline & 2. Within the Hour After Sexual Intercourse & 2. $41 \%$ \\
\hline & 3. Multiple Hours After Sexual Intercourse & 3. $14 \%$ \\
\hline & 4. The Following Day After Sexual Intercourse & 4. $7 \%$ \\
\hline
\end{tabular}

Table 4: Assessment of common methods used to reduce the discharge/ dripping of sexual fluids after intercourse.

\begin{tabular}{|c|c|c|}
\hline Question & Answer Choices & Response \\
\hline \multirow{5}{*}{$\begin{array}{l}\text { What do you currently do to reduce the discharge/ dripping of } \\
\text { sexual fluids after sexual activity? (Check all that apply) }\end{array}$} & 1. Shower/Wash & 1. $55 \%$ \\
\hline & 2. Urinate/Use the Toilet & 2. $53 \%$ \\
\hline & 3. Use a Towel or Wipe & 3. $51 \%$ \\
\hline & 4. I Currently Do Nothing & 4. $\quad 9 \%$ \\
\hline & 5. Other & 5. $\quad 0 \%$ \\
\hline
\end{tabular}

Once a total of 1,000 women who met the inclusion criteria was received, the survey was closed.

\section{Results and Discussion}

A total of 1,940 women completed the survey. 940 were excluded due to the aforementioned criteria. Demographics of the entire survey population is shown in Table 1 and Table 2. The majority of respondents were over 18 years of age, married or with a partner, and were white. Most were premenopausal and used tampons.

Approximately half (52\%) of women experienced semen seepage or drippling of fluids after intercourse. One in 4 women $(27 \%)$ stated they felt "unclean" after sex. As expected, other common complaints were urinary tract infection (21\%), vaginal odor (20\%), and yeast infections (13\%).
The subset of women who were bothered by seepage or drippling was analyzed. Most of these women experienced the dripping either immediately following ejaculation (71\%) and/ or within the hour $(42 \%)$ after completed sexual intercourse. A significant number of women (21\%) stated that the dripping/ seepage occurred several hours after intercourse $(14 \%)$ to the following day (7\%) (Table 3).

When specifically asked about their displeasure with vaginal discharge and seepage of sexual fluids after intercourse, $29 \%$ of women involved in the study admitted being moderately bothered, and $12 \%$ admitted being extremely bothered (Chart 1). 28\% of women reported to be interested in using a method to reduce amount of discharge or dripping of sexual fluids after intercourse (Chart 2). The most common methods women use to reduce the seepage are by either showering, washing, urinating, or using a towel and wiping (Table 4).

Table 5: Analysis of women who are moderately to severely bothered by vaginal discharge/ dripping of sexual fluids after intercourse.

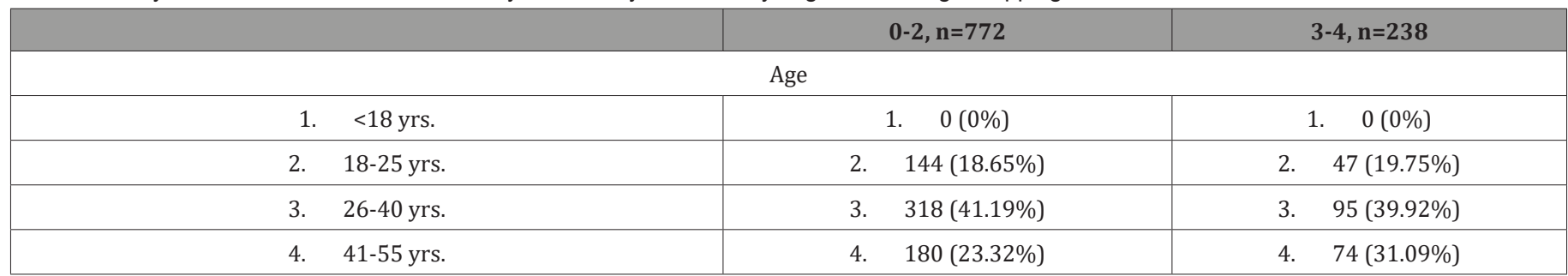




\begin{tabular}{|c|c|c|}
\hline 5. $>56$ yrs. & 5. $130(16.84 \%)$ & 5. $22(9.24 \%)$ \\
\hline \multicolumn{3}{|c|}{ Household Income } \\
\hline 1. $<\$ 49,999$ & 1. $346(44.82 \%)$ & 1. $117(49.16 \%)$ \\
\hline 2. $\$ 50,000-150,000$ & 2. $365(47.28 \%)$ & 2. $103(43.28 \%$ \\
\hline 3. $>\$ 151,000$ & 3. $61(7.9 \%)$ & 3. $18(7.56 \%)$ \\
\hline \multicolumn{3}{|c|}{ Highest Education } \\
\hline 1. High School or Equivalent & 1. $181(23.45 \%)$ & 1. $66(27.73 \%)$ \\
\hline 2. Some College & 2. $289(37.44 \%)$ & 2. $83(34.87 \%)$ \\
\hline 3. Bachelor's Degree & 3. $181(23.45 \%)$ & 3. $45(18.91 \%)$ \\
\hline 4. Graduate Degree or Higher & 4. $98(12.69 \%)$ & 4. $34(14.29 \%)$ \\
\hline 5. Other & 5. $23(2.98 \%)$ & $10(4.2 \%)$ \\
\hline \multicolumn{3}{|c|}{ Ethnicity } \\
\hline 1. Asian/ Pacific Islander & 1. $21(2.72 \%)$ & 1. $9(3.78 \%)$ \\
\hline 2. Black or African American & 2. $85(11.01 \%)$ & 2. $\quad 41(17.23 \%)$ \\
\hline 3. Hispanic or Latino & 3. $52(6.74 \%)$ & 3. $23(9.66 \%)$ \\
\hline 4. Other & 4. $26(3.37 \%)$ & 4. $\quad 3(1.26 \%)$ \\
\hline 5. White & 5. $588(76.17 \%)$ & 5. $162(68.07 \%)$ \\
\hline \multicolumn{3}{|c|}{ Relationship Status } \\
\hline 1. Divorced/Separated & 1. $62(8.03 \%)$ & 1. $19(7.98 \%)$ \\
\hline 2. Married or Have a Partner & 2. $547(70.85 \%)$ & 2. $164(68.91 \%)$ \\
\hline 3. Single (Never Married) & 3. $154(19.95 \%)$ & 3. $52(21.85 \%)$ \\
\hline 4. Widowed & 4. $9(1.17 \%)$ & 4. $3(1.26 \%)$ \\
\hline \multicolumn{3}{|c|}{ Sexual Orientation } \\
\hline 1. Bisexual & 1. $82(10.62 \%)$ & 1. $22(9.24 \%)$ \\
\hline 2. Heterosexual & 2. $669(86.66 \%)$ & 2. $209(87.82 \%)$ \\
\hline 3. Homosexual & 3. $0(0 \%)$ & 3. $0(0 \%)$ \\
\hline 4. Prefer Not to Answer & 4. $21(2.72 \%)$ & 4. $7(2.94 \%$ \\
\hline Sexually Active & 1. $772(100 \%)$ & 1. $238(100 \%)$ \\
\hline \multicolumn{3}{|c|}{ Sex Frequency } \\
\hline 1. A Few Times per Year & 1. $68(8.81 \%)$ & 1. $13(5.46 \%)$ \\
\hline 2. Daily & 2. $52(6.74 \%)$ & 2. $20(8.4 \%)$ \\
\hline 3. Monthly & 3. $154(19.95 \%)$ & 3. $40(16.81 \%)$ \\
\hline 4. Multiple Times per Week & 4. $238(30.83 \%)$ & 4. $80(33.61 \%)$ \\
\hline 5. Weekly & 5. $260(33.68 \%)$ & 5. $85(35.71 \%)$ \\
\hline \multicolumn{3}{|c|}{ Birth Control } \\
\hline 1. Intrauterine Device (IUD) & 1. $64(9.13 \%)$ & 1. $21(9.55 \%)$ \\
\hline 2. Male Condoms & 2. $0(0 \%)$ & 2. $0(0 \%)$ \\
\hline 3. No Active Use of Contraception & 3. $474(67.62 \%)$ & 3. $139(63.18 \%)$ \\
\hline 4. Oral Contraception & 4. $163(23.25 \%)$ & 4. $\quad 60(27.27 \%)$ \\
\hline \multicolumn{3}{|c|}{ Menstrual Status } \\
\hline 1. Peri-menopause & 1. $111(14.38 \%)$ & 1. $51(21.43 \%)$ \\
\hline 2. Post-menopausal & 2. $200(25.91 \%)$ & 2. $55(23.11 \%)$ \\
\hline 3. Pre-menopausal & 3. $461(59.72 \%)$ & 3. $132(55.46 \%)$ \\
\hline \multicolumn{3}{|c|}{ Menstrual Product } \\
\hline 1. Do Not Use & 1. $70(9.07 \%)$ & 1. $17(7.14 \%)$ \\
\hline 2. Other (e. g. menstrual cup) & 2. $22(2.85 \%)$ & 2. $6(2.52 \%)$ \\
\hline 3. Sanitary Pad & 3. $300(38.86 \%)$ & 3. $101(42.44 \%)$ \\
\hline
\end{tabular}




\begin{tabular}{|c|c|cc|}
\hline $4 . \quad$ Tampon & $4 . \quad 380(49.22 \%)$ & 4. & $114(47.9 \%)$ \\
\hline Vaginal Odor & $1 . \quad 126(16.32 \%)$ & 1. & $77(32.35 \%)$ \\
\hline Discharge/ Dripping of Sexual Fluids & $1 . \quad 396(51.3 \%)$ & 1. & $134(56.3 \%)$ \\
\hline Sensation of Feeling Unclean & $1 . \quad 168(21.76 \%)$ & 1. & $106(44.54 \%)$ \\
\hline Urinary Tract Infection & $1 . \quad 160(20.73 \%)$ & 1. & $61(25.63 \%)$ \\
\hline Vaginal/ Yeast Infection & $1 . \quad 84(10.88 \%)$ & 1. & $52(21.85 \%)$ \\
\hline
\end{tabular}

The responses to the question of how bothersome seepage of sexual fluids is were further analyzed (Table 5). When controlled for age, $39.9 \%$ of women aged $26-40$ were moderately to extremely bothered. $68.9 \%$ of women who were extremely bothered were married and 33.61\% reported having intercourse multiple times per week. Women who were extremely bothered also reported experiencing vaginal odor $(32.3 \%)$ and the sensation of feeling unclean $(44.5 \%)$.

Table 6: Analysis of women who would be likely to try method to reduce discharge/ dripping of sexual fluids after sexual activity.

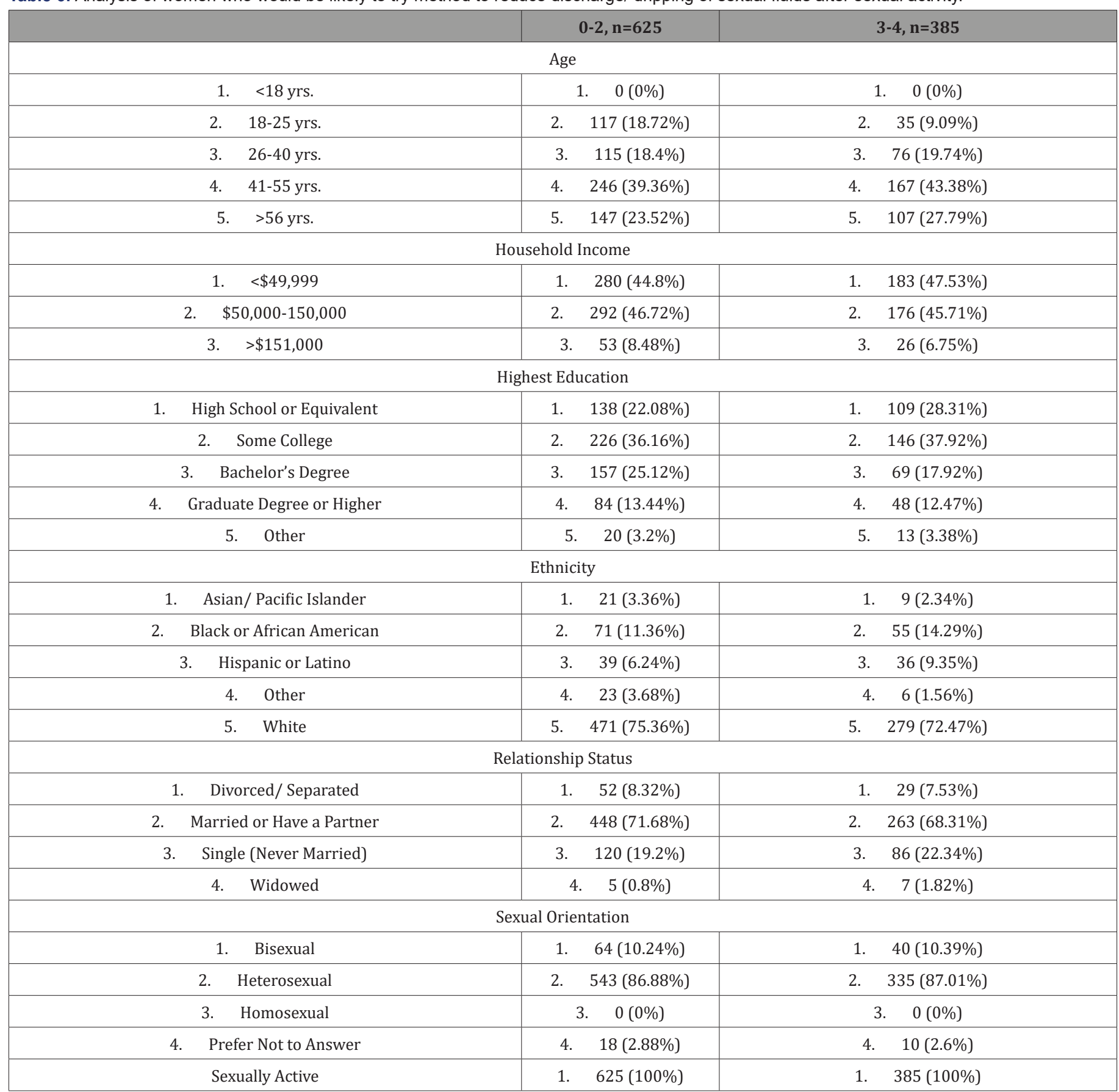




\begin{tabular}{|c|c|c|}
\hline \multicolumn{3}{|c|}{ Sex Frequency } \\
\hline 1. A Few Times per Year & 1. $56(8.96 \%)$ & 1. $25(6.49 \%)$ \\
\hline 2. Daily & 2. $45(7.2 \%)$ & 2. $27(7.01 \%)$ \\
\hline 3. Monthly & 3. $128(20.48 \%)$ & 3. $66(17.14 \%)$ \\
\hline 4. Multiple Times per Week & 4. $177(28.32 \%)$ & 4. $141(36.62 \%)$ \\
\hline 5. Weekly & 5. $219(35.04 \%)$ & 5. $126(32.73 \%)$ \\
\hline \multicolumn{3}{|c|}{ Birth Control } \\
\hline 1. Intrauterine Device (IUD) & 1. $47(8.23 \%)$ & 1. $38(10.86 \%)$ \\
\hline 2. Male Condoms & 2. $0(0 \%)$ & 2. $0(0 \%)$ \\
\hline 3. No Active Use of Contraception & 3. $400(70.05 \%)$ & 3. $213(60.86 \%)$ \\
\hline 4. Oral Contraception & 4. $124(21.72 \%)$ & 4. $99(28.29 \%)$ \\
\hline \multicolumn{3}{|c|}{ Menstrual Status } \\
\hline 1. Peri-menopause & 1. $93(14.88 \%)$ & 1. $69(17.92 \%)$ \\
\hline 2. Post-menopausal & 2. $174(27.84 \%)$ & 2. $81(21.04 \%)$ \\
\hline 3. Pre-menopausal & 3. $358(57.28 \%)$ & 3. $235(61.04 \%)$ \\
\hline \multicolumn{3}{|c|}{ Menstrual Product } \\
\hline 1. Do Not Use & 1. $64(10.24 \%)$ & 1. $23(5.97 \%)$ \\
\hline 2. Other (e. g. menstrual cup) & 2. $18(2.88 \%)$ & 2. $10(2.6 \%)$ \\
\hline 3. Sanitary Pad & 3. $247(39.52 \%)$ & 3. $154(40 \%)$ \\
\hline 4. Tampon & 4. $296(47.36 \%)$ & 4. $198(51.43 \%)$ \\
\hline Vaginal Odor & 1. $92(14.72 \%)$ & 1. $111(28.83 \%)$ \\
\hline Discharge/ Dripping of sexual fluid & 1. $297(47.52 \%)$ & 1. $233(60.52 \%)$ \\
\hline Sensation of Feeling Unclean & 1. $116(18.56 \%)$ & 1. $158(41.04 \%)$ \\
\hline Urinary Tract Infection & 1. $126(20.16 \%)$ & 1. $95(24.68 \%)$ \\
\hline Vaginal/ Yeast Infection & 1. $\quad 62(9.92 \%)$ & 1. $74(19.22 \%)$ \\
\hline
\end{tabular}

When further analyzing how likely women would be to try a new method to alleviate their symptoms, $43.4 \%$ of women aged 26-40 years old were moderately to extremely interested (Table 6). $41 \%$ of women who responded having a sensation of feeling unclean were extremely interested in a new method.

The purpose of this survey was to determine the prevalence of the complaint of seepage of semen after intercourse among sexually active women. The survey was able to identify this as not only a common problem, but also a significant bother which affects a women's sexual hygiene. Previous studies, including one by Bradshaw, have found that unprotected sexual activity is an important factor in determining the stability of the vaginal flora [4]. Prolonged semen exposure to the vaginal flora can lead to malodor and likely result in bacterial vaginosis causing itching and discomfort [5].

In our survey, $71 \%$ of women reported no use of barrier contraception ( $48 \%$ none, $17 \%$, oral contraceptives only, and $6 \%$ IUDs. $52 \%$ of the women reported having dripping of sexual fluids after intercourse. Despite more than half of the women in our study admitting to this complaint, physicians rarely discuss this issue in a clinical setting. Further, $41 \%$ of women continue to experience this dripping within an hour after intercourse, 14\% experience this multiple hours after intercourse, and 7\% of women experience this the following day. This implies that some women may even be bothered by this continued seepage of semen for more than 24 hours. Multiple women also further admitted to various complaints including sensation of feeling unclean, vaginal odor, and/or vaginal yeast infections after intercourse. It is plausible the continued exposure of the alkaline semen to the vaginal flora may be the cause of these complaints [6].

Knowing that semen stays present in the vagina for 12-36 hours after unprotected intercourse, women are putting themselves at increased risk of poor hygiene [2]. When directly asked how concerned they were by the continued semen seepage, $29 \%$ of women enrolled in the study said they were moderately bothered, and $12 \%$ admitted to being extremely bothered. A significant proportion of women stated they would be likely to use a method that would reduce the amount of seepage experienced, with $28 \%$ moderately likely and $19 \%$ extremely likely to try new methods. The women in our study used methods including showering, washing, urinating, or wiping. However, based on the number of women who admitted being moderately bothered by the continuous seepage, these methods are falling short in making women feel comfortable after sexual intercourse. New consumer products which are on the 
market addressing this aspect of sexual complaints may provide some benefit.

Limitations of this study include online sampling method and response bias. This was accounted for by screening the participants to meet our inclusion criteria. It is possible that women reached in an online survey may have different responses as opposed to women reached in a mailed survey. Response bias can also play a role, as women may not be as truthful in a survey on sexual practices and hygiene, as this can be an uncomfortable topic to address. Taking these biases into account, it can be postulated that the prevalence of semen seepage may be even higher than we report.

\section{Conclusion}

The prevalence of post-coital semen seepage in sexually-active women is high. Our study found that these women had significant bother not only from the immediate seepage, but also from the prolonged after-effects of odor and discomfort even hours after sex. The methods women are currently using to overcome this discomfort are not adequate. Consumer health products are needed to address this issue and to empower women to lower their risk of discomfort and odor after sexual intercourse.

\section{Acknowledgement}

This research project was sponsored by JBG NJ, LLC.

\section{Conflict of Interest}

Michael Ingber - Speaker/Proctor, Allergan, InMode, Hologic and Medtronic. Ownership/Financial Interest in After Clean Inc.

\section{References}

1. Sobecki J, Curlin F, Rasinski K, Lindau S (2012) What We Don't Talk about When We Don't Talk about Sex: Results of a National Survey of U.S. Obstetrician/Gynecologists. J Sex Med 9(5): 1285-1294.

2. Schwebke J, Richey C, Weiss H (1999) Correlation of behaviors with microbiological changes in vaginal flora. J Infect Dis 180(5): 1632-1636.

3. Gallo MF, Warner L, King CC, Sobel JD, Klein RS, et al. (2011) Association between semen exposure and incident bacterial vaginosis. Infect Dis Obstet Gynecol 2011: 1-10.

4. Chvapil M, Eskelson C, Jacobs S, Chvapil T, Russel DH (1978) Studies on vaginal malodor I. Study in humans. Obstet Gynecol 52(1): 88-93.

5. Bradshaw CS, Morton AN, Garland SM, Morris MB, Moss LM, et al. (2005) Higher-risk behavioral practices associated with bacterial vaginosis compared with vaginal candidiasis. Obstet Gynecol 106(1): 105-114.

6. Gordon N (1995) Semen responsible for fishy vaginal odor. J Fam Pract 40(6): 538-540. 